\title{
Genre analysis of writing tasks in Japanese university entrance examinations
}

Hideo Watanabed

Correspondence: hwat5050@uni. sydney.edu.au

University of Sydney, Sydney, New

South Wales 2006, Australia

\section{Springer}

\begin{abstract}
Background: English language writing is important in university entrance examinations in Japan and influences what learners and teachers do in English classes. This is especially noticeable in secondary education in Japan. While much research on university entrance examinations in Japan has been conducted, little attention has been paid to the types of writing required in these examinations.

Methods: This study draws on the notion of micro-genre developed by researchers of systemic functional linguistics (SFL) to investigate what micro-genres are required in writing tasks in the examinations. Fifty writing tasks appearing in examinations in 2013 were examined.
\end{abstract}

Results: It was found that only four micro-genres occurred in the examinations, namely expositions, personal reflections, discussions, and sequential explanations. Two micro-genres, expositions and personal reflections, amounted to $83.9 \%$ of the examined writing tasks. This tendency was seen even when micro-genres of the writing tasks by faculty type (science vs. humanities and arts) were identified.

Conclusions: The limited range of micro-genres prepared for the writing tasks in the examinations may greatly influence the activities of English writing teaching and learning in secondary education in Japan.

Keywords: Genre analysis, Systemic functional linguistics, Second language writing, Micro-genre, University entrance examination

\section{Background}

Japanese university entrance examinations and English writing tasks in those examinations

In several Asian countries, university entrance examinations have a significant impact on English language learning and teaching as scores in these examinations greatly affect students' chances of admission to a prestigious university and attendance at these universities is valued (see e.g., McMullen 2014 for Saudi Arabia; Yan et al. 2015 for China; Park et al. 2013 for Korea). In Japan, the university entrance examinations have provided considerable motivation for learners of English in Japanese secondary schools (see e.g., Tachibana et al. 1996; Taguchi et al. 2009). Japanese universities are ranked hierarchically by their reputation and one of the main reasons high school students study is to enter a respectable university (see e.g., Doyon 2001). Yoneyama (1999) explained that what is taught in Japanese high schools has been largely determined by what is required in Japanese university entrance examinations since competition-based

(c) 2016 Watanabe. Open Access This article is distributed under the terms of the Creative Commons Attribution 4.0 International License (http://creativecommons.org/licenses/by/4.0/), which permits unrestricted use, distribution, and reproduction in any medium, provided you give appropriate credit to the original author(s) and the source, provide a link to the Creative Commons license, and indicate if changes were made. 
education was adopted in Japan in the 1960s. In Japan, where the Japanese language is used almost exclusively in communication among citizens, there are very few opportunities for people to be exposed to other languages (Maher and Yashiro 1995). For this reason, university entrance examinations provide a strong motivation for Japanese learners of English to improve their English language proficiency. At the same time, the contents of the examinations have attracted criticism for lacking balance: the examinations focus too much on knowledge of grammar and do not test the English communicative proficiency of examinees (see e.g., Brown and Yamashita 1995; Guest 2007; Ichige 2006). Even though the examinations may motivate high school students to study English, the level of English proficiency of Japanese learners remains low. For example, Japan ranks as the twenty-seventh country out of thirty Asian countries in the Test of English as a Foreign Language (TOEFL) scores (Educational Testing Service 2014). The low level of English language proficiency of the Japanese may be related to English language teaching in Japan, which may be greatly influenced by the nature of university entrance examinations.

This paper examines university entrance examinations specifically in terms of the English writing tasks contained therein. Little research into English writing in the university entrance examinations has been conducted even though writing in English is of importance in both academic and professional fields (see e.g., Hyland 2009; Paltridge 2014 for discussions on English in academic discourse and Bhatia 2008 for a discussion on English in professional discourse). In this article, the term 'writing tasks' refers to free composition tasks in which examinees need to compose original texts on a given topic. Writing tasks such as summaries, translation from Japanese to English, and rearrangement of words to form a sentence are not included. Only in free composition tasks do examinees need to compose a text with a communicative purpose. An ability to compose a text which accomplishes a communicative purpose, Rose and Martin (2012) argue, is crucial to improving students' writing ability.

In Japan, there are two types of university entrance examinations: those prepared by a public institute, the National Center for University Entrance Examinations (NCUEE) and those prepared by the private universities. Examinees need to take the exam prepared by NCUEE in order to apply for entrance into public universities. In recent years, many private universities have begun to accept examinees' scores in the exam prepared by NUCEE for their applications. However, the number in offers allocated to such applications is limited. Many examinees still need to take the exams prepared by the private universities to which they are applying. Furthermore, even those who apply to public universities need to take examinations prepared by each of the public universities to which they are applying after taking the common exam prepared by NUCEE. Thus, examinations prepared by both public and private universities may be influential in how students learn English and how their teachers teach it to them.

Ito et al. (2007) compared the English tests prepared for university entrance examinations prepared by public institutions in Japan and Finland. In the Japanese test, tasks based on the rearrangement of word order were found to be the only writing tasks. The points assigned to these tasks amounted to $6 \%$ of the final score in the test. In the Finnish test, examinees needed to write English texts which were 150 to 200 words long, including texts that express their own opinions. The free composition task amounted to $47.4 \%$ of the final score in the English test. Ito et al. (2007) assert that 
the low allocation of marks to writing in the Japanese test may lead to a lack of teachers' attention to writing activities in Japanese high schools. The findings of this research also show differences in the proportions of marks allocated to writing tasks between the university entrance examinations prepared by public institutions in the two countries. The examinations prepared by the private Japanese universities have more varieties of writing tasks than those prepared by NUCEE. According to Kowata (2009), there are five types of writing tasks in these examinations: free composition, conditional composition, summary, translation from Japanese to English, and rearrangement of word order. In terms of free composition, however, only $20 \%$ of examinations included this type of writing task. Kowata (2009) analysed free composition tasks in Japanese university entrance examinations using a classification developed by Bain (1890) and found that the examinees were required to write mostly persuasive texts. This type accounted for $70 \%$ of all the writing tasks he examined. Therefore, Kowata (2009) claims that examinees may be given only a few opportunities to practice free composition and write other text types such as narrative and description even in the free composition tasks. However, Bain's classification fails to describe differences among persuasive texts. In particular, he does not draw the distinction between expositions and discussions. Writing tasks in the examinations need to be analysed using a classification developed more recently. More developed classifications may reveal the characteristics of the writing tasks more specifically. The findings may facilitate learning and teaching English writing in educational settings and contribute to an improvement of writing tasks in the examinations.

Writing tasks in the Japanese university entrance examinations have attracted the attention of Japanese researchers. Shiokawa (2000) examined 150 English texts written by high school students who had been preparing to take an examination for a specific university. He found that the correlations between the scores in the free composition task and those in the translation task and the reading task respectively were low. This may suggest that an ability to compose a text would not be improved by teaching students to translate Japanese texts to English or to read English. Shizuka (1996) argues that in writing classes in Japanese high schools, teachers' feedbacks on learners' writing can be effective since the learners think that the feedback leads to an advantage in writing tasks in university entrance examinations.

\section{The notion of genre}

In order to investigate what is required in the Japanese university entrance examinations in terms of English writing tasks, this study utilises the notion of genre as developed in Martin (1984). Martin's notion of genre is based on SFL as developed by Halliday (1978, 1985 , 1994). The main characteristics of SFL which underpin the notion of genre are its emphasis on the meaning of texts, choices in the use of language and the relations between the contexts of texts. SFL theorists assert that the use of language is influenced by the social and cultural contexts in which the language occurs (see e.g., Butt et al. 2012; Eggins 2004; Halliday 1978, 1985; Martin, 1992, 2009; Martin and Rose 2008). Genre is staged in the sense there are usually steps to constructing meaning, goal-oriented as these steps are organised with the aim of attaining something and social because genre is built within an interaction with others (Martin and Rose 2008; Rose and Martin 2012). The steps that a language user moves through in a genre are culturally specific (Martin 2009). 
There are two types of genre: macro-genre and micro-genre. Longer texts such as novels are classified as macro-genre (Martin 1994; Martin and Rose 2008). Martin (1997) defines micro-genres, such as arguments and reports, as elemental genres. Since writing in this tradition is goal-oriented, writers choose what and how to write depending on their communicative purposes in each genre as texts in different genres have typical schematic structures (see e.g., Butt et al. 2012; Christie and Derewianka 2008; Derewianka 1990; Martin and Rose 2008; Rose and Martin 2012; Rothery 1994).

Martin and Rothery (1981) present seven micro-genres that are typical of primary and secondary school writing in Australia: observations/comments, recounts, reports, narratives, expositions, thematic narratives, and literacy criticisms. In each microgenre, there is a structural pattern, which is called its schematic structure. Schematic structures present specific stages for each micro-genre (see e.g., Eggins 2004; Martin 1992). Each stage in the schematic structure of a text is instrumental in constructing a genre as the stages enable the genre to achieve its communicative purpose (Eggins 2004). Martin and Rothery (1981) analysed texts written by young children in kindergarten and in years 1 and 2 in primary schools in Australia to identify what microgenres the children were taught to write. They found that the main micro-genres were narrative ones such as comments, recounts, and reports. Martin and Rothery (1981) argue that young learners need to be provided with more varieties of micro-genre to be successful in English writing. Woodward-Kron (2002) investigated the micro-genres found in twenty essays assigned in a Department of Education at an undergraduate level in an Australian university. She found that, while all the essays could be classified as either expositions or discussions, other micro-genres such as descriptive reports and exemplums were embedded within them. Chen and Foley (2004) investigated English texts classified as expositions written by fifty Chinese university students. They examined the students' use of nominalisation (Halliday 1998) such as pollution as a norm form of the verb, pollute. It was found that their use of nominalisation was inappropriate especially when they described participants or things. Chen and Foley (2004) argue that it is important to teach how to write an exposition text and how grammatical items contribute to the construction of an exposition text.

Very little research into micro-genres in different English as a foreign language (EFL) settings has been done. Martin (2009) claims that genre-based pedagogy may be beneficial to second language (L2) learning even though it has not been examined as deeply as that for L1 learning. To the writer's knowledge, however, no research has been conducted into micro-genres of writing tasks in university entrance examinations. Brown (2004) argues that assessments such as university entrance examinations exhibit washback, which refers to the effect an assessment has on teaching and learning. As mentioned in the previous section, university entrance examinations may have a strong effect on both teaching and learning English in Japan as well as in other Asian countries.

\section{Genre and L2 English writing pedagogy}

Recently, the notion of genre has played a significant role in the teaching of L2 writing. The notion of genre was originally developed for literacy education in Australia in the 1980s and has also been adopted in literacy education in the UK (see Christie 2013). In another context, English as a second language (ESL), the effectiveness of genre-based 
teaching has also been reported. This is exemplified in the work undertaken in the U.S. by Harman (2013), Bunch and Willett (2013), and de Oliveira and Lan (2014). Harman (2013) reported that the genre-based teaching of narrative texts to L2 fifth-year learners in an elementary school developed their lexical cohesion. Bunch and Willett (2013) analysed exposition texts written by forty L2 middle school students. The analysis revealed that the students utilised linguistic resources which they learnt in various school subjects when they wrote exposition texts. de Oliveira and Lan (2014) conducted a case study which focused on the development of procedural recount texts produced by one ESL learner in an elementary school. A teaching/learning circle which comprises of deconstruction, joint construction, and independent construction developed by Martin and Rose (2005) was adopted to teach a procedural recount text. In the study of de Oliveira and Lan (2014), the school-aged participant improved both his lexical and rhetorical abilities of writing. The goal of the genre-based method is to promote learners' independence as writers while it encourage teachers to explicitly teach how a certain genre is linguistically constructed.

In an EFL context, Emilia and Hamied (2015) reported that a genre-based teaching in an Indonesian university, which focused on the teaching of exposition texts improved learners' writing ability. After the teaching, the learners reported via a questionnaire that they considered the teaching to have been effective and that they were aware of their improvement in English writing. The works of Wang (2013) and Yasuda (2011) both focused on instruction based upon macro-genre (see the previous section for an explanation of macro-genre). Wang provided a sixteen-week writing program to students in a Chinese university and Yasuda observed Japanese students who were offered writing classes specialised in email writing in a Japanese university. Both researchers articulated that the genre-based teaching enhanced not just writing proficiency in a specific macrogenre but their learners' awareness of distinctive language use in different macro-genres. The findings in the research articulated above support the usefulness of genre-based pedagogies in L2 writing instruction. The findings may also endorse the importance of genre analysis of the writing tasks in university entrance examinations as the examinations have washback (see the previous section for an explanation of washback).

\section{Research questions}

This article aims to answer the following questions:

1. What micro-genres are required in the writing tasks of Japanese university entrance examinations?

2. To what extent does each of the micro-genres found in the examinations account for of all the examined tasks?

\section{Methods}

\section{Sets of genre classifications used in this article}

The classification of micro-genres used in this paper is based on the work of Martin and Rose (2008) and Humphrey et al. (2012). Table 1 shows the classification of microgenres adopted in this study. The classification developed by the genre researchers based in SFL for primary and secondary school students in an English speaking country (see e.g., Humphrey et al. 2012; Martin and Rose 2008; Rose and Martin 2012) may be 
Table 1 Classification of micro-genres adopted in this article

\begin{tabular}{|c|c|c|}
\hline Micro-genre & Communicative purpose & Schematic structure ( $\wedge$ means followed by) \\
\hline $\begin{array}{l}\text { Sequential explanations } \\
\text { (Martin and Rose 2008) }\end{array}$ & $\begin{array}{l}\text { To show a series of events } \\
\text { and their reasons }\end{array}$ & Phenomenon $\wedge$ explanation \\
\hline $\begin{array}{l}\text { Expositions } \\
\text { (Martin and Rose 2008) }\end{array}$ & $\begin{array}{l}\text { To persuade a reader to } \\
\text { think in a certain way }\end{array}$ & Thesis $\wedge$ argument $\wedge$ reiteration \\
\hline $\begin{array}{l}\text { Discussions } \\
\text { (Humphrey et al. 2012) }\end{array}$ & $\begin{array}{l}\text { To explore an issue from } \\
\text { various perspectives }\end{array}$ & $\begin{array}{l}\text { Identification of issue } \wedge \text { arguments for } \wedge \text { arguments } \\
\text { against } \wedge \text { conclusion } / \text { recommendation }\end{array}$ \\
\hline
\end{tabular}

appropriate for the analysis of the writing tasks set for mainly secondary school students in Japan other than those developed for English writing in tertiary education. Martin and Rose (2008) present a wide range of micro-genres which consist of stories, histories, reports and explanations, and procedures and procedural recounts, and other specific micro-genres such as sequential explanations or expositions. Humphrey et al. (2012) also provide detailed examples of these micro-genres. The analysis in this study is mainly based on the genre classification of Martin and Rose (2008), together with the classifications proposed by Humphrey et al. (2012) where more detailed explanations are required.

Expositions can be further classified into two types: analytical and hortatory (see e.g., Martin 1985; Humphrey et al. 2012). The analyses of expositions in this study follow those developed by Humphrey et al. (2012). Descriptions of these two types of expositions are shown in Table 2.

\section{Data collection and analysis}

The writing tasks in university entrance examinations in a central area of Japan in 2013 were collected using Xam (JC Educational Institute 2013) software. The software provides examples of tasks that were in previous examinations in a variety of departments of universities in Japan as each department of the universities prepares its own examinations. Fifty tasks were collected for the analyses. In terms of sources which examinees need to use, many of the writing tasks required only prior knowledge and only a few tasks used primary sources (texts provided in the examinations) (see Taylor 1989). This was exemplified in questions or directions such as "When you were a child, what were you afraid of?" and "Give two examples of how technology can help you to learn English" for the prior knowledge type. An example of a task which involved primary sources is a direction such as "Reply to the following email...".

The reason only writing tasks in the examinations of universities in the central area of Japan were chosen is that the area has more universities than any other area of Japan. In this area, there are 257 universities out of 783 in Japan according to the ministry of education, culture, sports, science and technology-Japan (MEXT) (2013).

Table 2 Types of Expositions

\begin{tabular}{lll}
\hline $\begin{array}{l}\text { Types of } \\
\text { Expositions }\end{array}$ & Communicative purpose & Schematic structure \\
\hline $\begin{array}{lll}\text { Exposition } \\
\text { (analytical) }\end{array}$ & $\begin{array}{l}\text { To have readers think in a } \\
\text { certain way }\end{array}$ & $\begin{array}{l}\text { Background } \wedge \text { statement of position } \wedge \text { series of arguments } \wedge \\
\text { reinforcement of position }\end{array}$ \\
$\begin{array}{l}\text { Exposition } \\
\text { (hortatory) }\end{array}$ & $\begin{array}{l}\text { To have readers take a } \\
\text { certain action }\end{array}$ & $\begin{array}{l}\text { Appeal for action } \wedge \text { arguments (suggested actions) } \\
\text { reinforcement of appeal }\end{array}$ \\
\hline
\end{tabular}


An inter-coder reliability test was conducted, the coders being the writer and a research assistant. The test drew on Cohen's kappa that calculates a degree of agreement between multiple coders, rectifying some agreement which occurs by chance (see Loewen and Plonsky 2015). The author provided the research assistant with explanations of the rubrics and she analysed the writing tasks independently. Agreement for each of the rubrics used in this article was calculated. Scores provided by the test were 0.9 for expositions (analytical), 0.4 for expositions (hortatory), 1.0 for personal reflections (opinion), 0.7 for personal reflections (imaginary), 0.9 for personal reflections (descriptive), 0.8 for discussions, 1.0 for sequential explanation, and 1.0 for an unclear task. Even though there is no common standard as to what score represents an acceptable score, scores as low as 0.7 can generally be considered to indicate an acceptable level of agreement (Fleiss et al. 2003). With this standard, all the classifications of the rubrics except for expositions (hortatory) can be considered to be at an acceptable level of agreement. The reason why the score for expositions (hortatory) was low may be attributed to the complexity of the two types of expositions, hortatory and analytical. For a writing task in the examinations such as "Do you think that rich countries should give aid to poor countries?", examinees can write an essay to justify their ideas or convince people in rich countries to take some action.

The writing tasks in the 2013 university entrance examinations were classified into micro-genres. Then, the frequency of each micro-genre that appeared in the writing tasks was counted.

\section{Results}

This section shows the result of the analysis of micro-genres in the writing tasks presented in the university entrance examinations on the basis of their classifications into micro-genres. Table 3 presents the micro-genres that appeared in the Japanese university entrance examinations. The results show that there are four micro-genres in the writing tasks. The frequency of each micro-genre, however, varies greatly.

The common micro-genres were expositions (42.8\%) and personal reflections (41.1\%) each of which contributed almost half of the all the writing tasks in the examinations. An example of an exposition is "Is fast food a good thing or a bad thing? Present reasons for your opinion," which was prepared by Meiji Gakuin University. In this task type, examinees were asked to write an English text which attempts to persuade readers to think in a certain way.

In personal reflection tasks, examinees are required to write about their feelings, favourite things or ideas. An example of such a task is "When making a choice, do you first or foremost consider what you want, what will make you happy, or do you consider what is best for you and the people around you?", which was set by Tokyo

Table 3 Micro-genres of the writing tasks

\begin{tabular}{llc}
\hline Micro-genre & Number & Proportion in percentages \\
\hline Expositions & ${ }^{\mathrm{a}}{ }^{\mathrm{b}} 24$ & 42.8 \\
Personal reflections & $\mathrm{b}_{23}$ & 41.1 \\
Discussions & ${ }^{\mathrm{a}} 8$ & 14.3 \\
Sequential explanations & 1 & 1.8 \\
\hline
\end{tabular}

${ }^{\mathrm{a}}$ Five tasks were judged to be both exposition and discussion texts. These tasks were therefore included in the count for both expositions and discussions.

$\mathrm{b}_{\text {In }}$ one task, examinees were told to choose one out of two writing tasks. 
Gakugei University. In some personal reflection tasks, examinees are required to give their opinions. However, they only need to express their thoughts without attempting to persuade readers to think in a certain way or to take a certain action, making them different to expositions. The micro-genre of personal reflections is not found in the classification of micro-genres in the genre researchers. The deeper analysis of personal reflection tasks in the examinations is shown in the latter part of this section. Discussion texts amounted to $14.3 \%$ of the writing tasks. In the discussion tasks, examinees need to answer questions such as "Should Japanese universities start in September instead of April? What would be the advantages and disadvantages of making that change?", which was prepared by Meiji Gakuin University. Only one sequential explanation task was found in all the tasks which was "Write a paragraph in ENGLISH giving your own interpretation of BOTH the likely CAUSES and CONSEQUENCES of this situation," which was prepared by Waseda University. This task has a clear statement in the task explanation telling examinees to write a cause and consequence type text.

This result shows that the variation in micro-genres in the writing tasks was limited. It was also found that only two micro-genres, expositions and personal reflections, accounted for roughly $80 \%$ of all the four micro-genres found in the writing tasks.

Exposition tasks were categorised into two types: analytical and hortatory. Table 4 shows the types of exposition tasks in the examinations. Most of the exposition tasks were analytical (79.2\%), while only five exposition tasks (20.8\%) were found to be hortatory. Regarding analytical tasks, tasks such as "Do you think there are any advantages for students to have a portable computer at high school? Why or why not?", which was set by the University of Tokyo were provided. In the hortatory tasks, tasks such as "What can we do to save electricity? Give specific examples and explain how they would help," which was prepared by Meiji Gakuin University were given.

Personal reflection tasks were analysed to clarify what kind of texts students were required to write. There are three types of personal reflections: descriptive, imaginary, and opinion.

The opinion type is the most common (39.1\%) in the personal reflections category. In this type, examinees are told to write their opinion in the absence of a persuasive attitude in tasks such as 'What is important to you in choosing what you wear?', which was prepared by Aoyama Gakuin University. Seven tasks (30.4\%) were classified as a descriptive type in which writers need to write a text that describes things or ideas such as 'Write about a book which you want to be translated into English and give reasons', which was prepared by Seisen Women's University. The imaginary type, whose purpose is to explain or describe an imaginary thing, accounted for $26.1 \%$ (six tasks). One of the tasks in this type is 'If you could start your own company, what would it be, and why?' which was prepared by Aoyama Gakuin University. One task asks examinees to write an email text with instructions on what information should be included. This task is classified as an unclear task. Table 5 shows the numbers of tasks of each type of personal reflection task and their proportions in percentage terms.

Table 4 Types of expositions in the writing tasks in the examinations

\begin{tabular}{llc}
\hline Type of expositions & Number & Proportion in percentages \\
\hline Analytical & 19 & 79.2 \\
Hortatory & 5 & 20.8 \\
\hline
\end{tabular}


Table 5 Types of personal reflections in the writing tasks in the examinations

\begin{tabular}{llc}
\hline Types & Number & Proportions in percentages \\
\hline Opinion & 9 & 39.1 \\
Descriptive & 7 & 30.4 \\
Imaginary & 6 & 26.1 \\
Unclear & 1 & 4.4 \\
\hline
\end{tabular}

The writing tasks were also classified by faculty type: science vs. humanities and arts. Science faculties include medicine, nursing, and engineering and humanities and arts faculties include literature, law, economics, and intercultural communication. Table 6 shows the numbers and proportions in percentage term of the micro-genres by faculty type. One college was included in both types as it was a combination of economics and engineering science. The proportions in the two college types showed a similar representation of what micro-genres are required in the examinations. In the two faculty types, expositions and personal reflections amounted to $84.6 \%$ (science) and $84.8 \%$ (humanities and arts) with expositions accounting for $46.1 \%$ and $41.3 \%$ respectively.

Salient differences include the fact that the proportion of personal reflections (46.1\%) outnumbered that of expositions in humanities and arts (38.5\%) and science faculties did not prepare a task which requires examinees to write a sequential explanation text.

\section{Discussions}

In this section, the findings of the analysis are discussed with regard to the previous research on English writing tasks in university entrance examinations in Japan and the previous studies into appropriate micro-genres in educational settings. The four microgenres found in the writing tasks of the Japanese entrance examinations were compared with results from previous research into the classification of the writing tasks in Japanese entrance examinations and the question of whether those micro-genres are an appropriate set of micro-genres for the Japanese university entrance examinations was investigated. Firstly, the question of how similar or different the findings in this article were with those of Kowata's (2009) study was explored. Kowata (2009) followed Bain's (1890) classification of texts, which consists of narrations, descriptions, expositions, and argumentations to analyse the writing tasks in the Japanese university entrance examinations. 'Expositions' in Bain's classification are similar to the term, 'explanations' adopted in this article. Kowata (2009) found that most of the tasks were argumentations (70.0 \%) followed by narrations (10.0\%), expositions (9.33\%), descriptions (5.33\%), and others (5.33\%). The findings of his study and this article are similar in

Table 6 Micro-genres of the writing tasks by faculty type (science vs. humanities and arts)

\begin{tabular}{|c|c|c|c|c|}
\hline \multirow[b]{2}{*}{ Micro-genre } & \multicolumn{2}{|l|}{ Science } & \multicolumn{2}{|c|}{ Humanities and arts } \\
\hline & Number & $\begin{array}{l}\text { Proportions } \\
\text { in percentages }\end{array}$ & Number & $\begin{array}{l}\text { Proportions } \\
\text { in percentages }\end{array}$ \\
\hline Expositions & 6 & $46.1 \%$ & 19 & $41.3 \%$ \\
\hline Personal reflections & 5 & $38.5 \%$ & 20 & $43.5 \%$ \\
\hline Discussions & 2 & $15.4 \%$ & 6 & $13.0 \%$ \\
\hline Sequential explanations & 0 & $0.0 \%$ & 1 & $2.2 \%$ \\
\hline
\end{tabular}


that the most common task type is persuasive writing. Most of the writing tasks in the examinations, $83.9 \%$, examined in this article may be categorised into Bain's argumentations when the tasks of expositions, discussions and opinion and imaginary in personal reflections in the present study are combined together. The small differences may have occurred as the two studies took place in different years; this study examined the examinations in 2013 and Kowata's study looked into university examinations in 2006. This article, however, identifies communicative purpose in greater detail than Kowata did. Thus, the writing tasks which were categorised into argumentations in Kowata's study can be further classified into micro-genres such as expositions, discussions, and personal reflections.

The range of micro-genres in the Japanese university entrance examinations is very narrow compared to that reported in previous research into micro-genres (see e.g., Butt et al. 2012; Christie and Derewianka 2008; Derewianka 1990; Humphrey et al. 2012; Martin and Rose 2008; Rothery 1994). This situation may perhaps inhibit Japanese learners' writing development. Being able to write various micro-genres is necessary for English language learners as different experiences are expressed through the use of different micro-genres (Rose and Martin 2012). For example, in the field of science and history, in which facts and events are often discussed respectively, students are often required to write explanation texts which usually include a cause-and-effect structure (Rose and Martin 2012). Rothery (1985) claims that reports and expositions are two significant micro-genres for language learners, but different structures in the two micro-genres are generated by the different communicative purpose of each microgenre. Expositions which are the most common micro-genre in the university entrance examinations may be a very significant micro-genre to be able to write as Martin (1980; 1985) claims that expositions are highly regarded in university writing. Also, both of the subordinate types of expositions, namely analytical and hortatory, were found in the examinations. However, exposition texts may be represented by micro-genres such as explanations and information reports. Exposition texts written for assignments in tertiary education in an Australian university were found to include descriptive microgenres to connect arguments in the texts (Woodward-Kron 2005). Descriptive microgenres such as information reports were not found in the writing tasks in the university entrance examinations. Other micro-genres such as story or procedure types were also not found. It can be considered that Japanese universities included exposition tasks so that they could also assess other micro-genres embedded in texts written by examinees. However, the word limits for the writing tasks, which were usually around one hundred and fifty words may limit examiners from including micro-genres such as explanations and information reports in exposition texts.

There were slight differences in which micro-genres were included in the examinations by faculty type. The most remarkable difference may lie in in the fact that, in the faculties of humanities and arts, the number of personal reflection tasks outnumbered that of expositions. These faculties might consider that it is more important for examinees to be able to write their opinions or descriptions of things or events than the faculties of science do. More generally, the faculties of humanities and arts might place more importance on English writing. This can be deduced from the fact that they prepared forty-six writing tasks while those of science numbered only thirteen texts. 
As the university entrance examinations are one of the major factors that motivate and influence high school and even younger students in Japan (see e.g., Doyon 2001; Oda 2007; Shizuka 1996; Tachibana et al. 1996; Yoneyama 1999), a narrow range of micro-genres in the examinations may lead to those students being able to successfully write texts in only a limited range of micro-genres.

Personal reflections, which amount to $41.1 \%$ of all the writing tasks in the examinations, are close to the micro-genre, comments. Martin and Rothery (1981) found that comments was the most common micro-genre among students in years 1 and 2 of primary schools in Australia when they examined micro-genres written among students' written texts. Texts within this micro-genre were written when students were provided with topics and asked to write about a topic without instruction on how they should construct their texts. Thus, by practicing to write comment texts, students are less likely to learn the various micro-genres that are required to be successful in school (Martin and Rothery 1981).

Rothery (1994) describes personal responses, which is similar to personal reflections found in the examinations, as writers respond to a text, as the micro-genre that contributes the least to learners' writing development since this micro-genre does not involve explanations or interpretations. Thus, the fact that personal reflections amount to almost half of the writing tasks in the university examinations may not contribute to developing high school students' writing ability. In the writing textbooks for high school students approved by MEXT, which are considered to reflect the goals of learning English set by MEXT, no personal reflection texts were found (Watanabe 2013). This may mean that MEXT considers personal reflections not to be significant. All the universities whose writing tasks were examined in this article claimed that their examinations were prepared based upon the course guidelines set for high schools by MEXT (1999). Even though the course guidelines do not clearly state which micro-genres should be taught in Japanese high schools, they claim that high school students need to be taught to effectively compose different English texts depending on the contexts of the texts. This may mean that high school students in Japan should be provided with a variety of micro-genres. Overall, the limited range of micro-genres appearing in the examinations may result in the restriction of the development of learners' writing proficiency as learners can conceivably assume that other microgenres which are not in the examinations are not as significant as those in the examinations.

The range of micro-genres in the examinations may not be able to be simply compared with those developed or found by genre researchers mainly based in Australia (see e.g., Butt et al. 2012; Christie and Derewianka 2008; Derewianka 1990; Humphrey et al. 2012; Martin and Rose 2008; Rothery 1994), as the microgenres in the Japanese examinations were set for an EFL context and those found in Australian curriculums were developed in an ESL context. Thus, a range of micro-genres in the examinations may not need to be the same as those in ESL contexts. The fact that personal reflections account for $41.1 \%$, while only one sequential explanation and no descriptive micro-genres exist in the Japanese examinations, as mentioned previously in this section, may limit students' success in writing texts in other micro-genres. Therefore, this may need to be amended. 


\section{Conclusions}

This article investigated the micro-genres of the writing tasks which appeared in university entrance examinations in Japan as university entrance examinations hold a strong influence on learning and teaching English. The analysis was carried out with the notion of micro-genres developed by genre researchers who draw on SFL. It was found that only a limited variety of micro-genres were required in the university entrance examinations and one of the major micro-genres in the examinations may not be suitable with respect to improving the English writing of high school students in Japan. The findings were discussed with regard to the previous studies into Japanese university entrance examinations and micro-genres.

\section{Limitations of the study and directions for further research}

The ethnographic approach to English language learners was not adopted in this study. More information on the influences of the writing tasks would be gained if researchers could interview learners or conduct a questionnaire on how the writing tasks and the texts affect their learning. This may reveal how much attention learners pay to the writing tasks. This study employed fifty writing tasks in the examinations of universities in central Japan. More samples from other areas in Japan would perhaps build more reliability into data on the range of micro-genres required in the examinations. This study, further, examined only the writing tasks set in 2013. An examination of tasks in multiple years may offer a more precise range of micro-genres than that found in the present study.

\section{Abbreviations}

EFL: English as a foreign language; ESL: English as a second language; L2: Second language; MEXT: Ministry of education, culture, sports, science and technology; NCUEE: National Center for University Entrance Examinations; SFL: Systemic functional linguistics.

Competing interests

The author declares that he has no competing interests.

Received: 27 October 2015 Accepted: 19 February 2016

Published online: 10 March 2016

\section{References}

Bain, A. (1890). English composition and rhetoric. NewYork: D. Appleton and company.

Bhatia, V. K. (2008). Genre analysis, ESP and professional practice. English for Specific Purposes, 27(2), 161-174.

Brown, H. D. (2004). Language assessment: Principles and classroom practices. Boston: Allyn \& Bacon.

Brown, J. D., \& Yamashita, S. O. (1995). English language entrance examinations at Japanese universities: What do we know about them? JALT Journal, 17, 7-30.

Bunch, G. C., \& Willett, K. (2013). Writing to mean in middle school: Understanding how second language writers negotiate textually-rich content-area instruction. Journal of Second Language Writing, 22(2), 141-160.

Butt, D., Fahey, R., Feez, S., \& Spinks, S. (2012). Using functional grammar: An explorer's guide (3rd ed.). Sydney: National Centre for English Language Teaching and Research, Macquarie University.

Chen, Y., \& Foley, J. (2004). Problems with the metaphorical reconstrual of meaning in Chinese EFL learners' expositions. In L. Ravelli \& R. A. Ellis (Eds.), Analysing academic writing: Contextualized frameworks (pp. 190-209). London: Continuum

Christie, F. (2013). Genres and genre theory: A response to Michael Rosen. Changing English, 20(1), 11-22.

Christie, F., \& Derewianka, B. (2008). School discourse: Learning to write across the years of schooling. New York: Continuum.

de Oliveira, L. C., \& Lan, S.-W. (2014). Writing science in an upper elementary classroom: A genre-based approach to teaching English language learners. Journal of Second Language Writing, 25, 23-39.

Derewianka, B. (1990). Exploring how texts work. Rozelle: Primary English Teaching Association.

Doyon, P. (2001). A review of higher education reform in modern Japan. Higher Education, 41(4), 443-470.

Eggins, S. (2004). An introduction to systemic functional linguistics (2nd ed.). London: Pinter.

Educational Testing Service. (2014). Test and score data summary for TOEFL IBT tests. http://www.ets.org/s/toefl/pdf/ 94227_unlweb.pdf. Accessed October 3, 2015.

Emilia, E., \& Hamied, F. A. (2015). Systemic functional linguistic genre pedagogy (SFL GP) in a tertiary EFL writing context in Indonesia. TEFLIN Journal, 26(2), 155-182.

Fleiss, J. L., Levin, B., \& Paik, M. C. (2003). Statistical methods for rates and proportions. New Jersey: John Wiley \& Sons. 
Guest, M. (2007). A Response to Yoko Ichige's "validity of center examinations for assessment of communicative ability". On Cue, 15(1), 28-32.

Halliday, M. A. K. (1978). Language as social semiotic: The social interpretation of language and meaning. London: Edward- Arnold

Halliday, M. A. K. (1985). Part A. In M. A. K. Halliday \& R. Hassan (Eds.), Language, context, and text: Aspects of language in a social-semiotic perspective (pp. 3-49). Waurn Ponds: Deakin University.

Halliday, M. A. K. (1994). An introduction to functional grammar (2nd ed.). London: Edward- Arnold.

Halliday, M. A. K. (1998). Things and relations: Regrammaticising experience as technical knowledge. In J. R. Martin \& R. Veel (Eds.), Reading science: Critical and functional perspectives on discourses of science (pp. 185-236). New York; London: Routledge.

Harman, R. (2013). Literary intertextuality in genre-based pedagogies: Building lexical cohesion in fifth-grade L2 writing. Journal of Second Language Writing, 22(2), 125-140.

Humphrey, S., Droga, L., \& Feez, S. (2012). Grammar and meaning. Newtown: PETAA.

Hyland, K. (2009). Academic discourse: English in a global context. New York: Continuum.

Ichige, Y. (2006). Validity of center examinations for assessment of communicative ability. On Cue, 14(2), 13-22.

Ito, H., Kawamura, A., Shimada, Y., Nishihara, M., \& Funato, S. (2007). Daigaku shingaku yoteisha wo taishou to shita eigo nouryoku shiken no kokusai hikaku -nihon no daigaku nyuushi to Finland no Matriculation Examination wo taishou ni- The international comparison of English proficiency tests for university entrances -The National Centre Test in Japan and Matriculation Examination in Finland as subjects-]. Bulletin of Shikoku English language Education Society, $27,11-26$.

JC Educational Institute. (2013). Xam. Chiba: JC Educational Institute.

Kowata, T. (2009). The possibility of washback effects in the context of Japanese university entrance examinations: Focusing on the analysis of writing tests. Language, Area and Culture Studies, 15, 81-93.

Loewen, S., \& Plonsky, L. (2015). An A-Z of applied linguistics research methods. London: Palgrave Macmillan.

Maher, J. C., \& Yashiro, K. (1995). Multilingual Japan: An introduction. Journal of Multilingual and Multicultural Development, 16(1-2), 1-17.

Martin, J. R. (1980). Writing project: Paper 2, Exposition: Literacy Criticism. Working Papers in Linguistics, 1, 1-34.

Martin, J. R. (1984). Language, register and genre. In R. M. Bunbury, F. Christie, S. Dawkins, \& Deakin University School of Education. Open Campus, P (Eds.), Language studies, children writing (pp. 21-30). Waurn Ponds: Deakin University.

Martin, J. R. (1985). Factual writing: Exploring and challenging social reality. VIC: Deakin University.

Martin, J. R. (1992). English text: System and structure. Amsterdam: John Benjamins.

Martin, J. R. (1994). Macro-genres: The ecology of the page. Network, 21, 29-52.

Martin, J. R. (1997). Analysing genre: Functional parameters. In F. Christie \& J. R. Martin (Eds.), Genre and institutions: Social processes in the workplace and school (pp. 3-39). New York: Continuum.

Martin, J. R. (2009). Language, register and genre. In C. Coffin, T. Lillis, \& K. A. O'Halloran (Eds.), Applied Linguistics Methods: A Reader: Systemic functional linguistics, critical discourse analysis and ethnography (pp. 12-32). London: Routledge.

Martin, J. R. (2009). Genre and language learning: A social semiotic perspective. Linguistics and Education, 20(1), 10-21.

Martin, J. R., \& Rose, D. (2005). Designing literacy pedagogy: Scaffolding democracy in the classroom. In R. Hasan, C. M. I. M. Matthiessen, \& J. Webster (Eds.), Continuing discourse on language: A functional perspective (pp. 251-280). London: Equinox.

Martin, J. R., \& Rose, D. (2008). Genre relations: Mapping culture. Oakville: Equinox Pub.

Martin, J. R., \& Rothery, J. (1981). Writing project report No.2. Working Papers in Linguistics.

McMullen, M. G. (2014). The value and attributes of an effective preparatory English program: Perceptions of Saudi university students. English Language Teaching, 7(7), p131.

Ministry of Education, Culture, Sports, Science and Technology-Japan (MEXT). (1999). Koutougakkou Gakushuusidouyouryou kaisetsu gaikokugo hen eigo hen [the explanation of the course of study for foreign languages and English for high schools]. Tokyo: Kairyudo.

Ministry of Education, Culture, Sports, Science and Technology-Japan (MEXT). (2013). Monbukagaku toukei youran [a statistical survey of education, culture, sports, science and technology]. http://www.mext.go.jp/b_menu/toukei/002/ 002b/1337986.htm Accessed 29th December 2013.

Oda, M. (2007). Globalization or the world in English: Is Japan ready to face the waves? International Multilingual Research Journal, 1(2), 119-126.

Paltridge, B. (2014). Genre and second-language academic writing. Language Teaching, 47(3), 303-318.

Park, H., Behrman, J. R., \& Choi, J. (2013). Causal effects of single-sex schools on college entrance exams and college attendance: Random assignment in Seoul high schools. Demography, 50(2), 447-469.

Rose, D., \& Martin, J. R. (2012). Learning to write, reading to learn: Genre, knowledge and pedagogy in the Sydney school. Sheffield: Equinox.

Rothery, J. (1985). Reading 1: Two varieties of writing: Report and Exposition. In J. Martin. (Ed.), Factual writing: exploring and challenging social reality (pp. 71-82). VIC: Deakin University.

Rothery, J. (1994). Exploring literacy in school English (write it right resources for literacy and learning). Sydney: Metropolitan East Disadvantaged Schools Program.

Shiokawa. (2000). An analysis of students' performance in writing tests in Japanese university entrance examinations: Focus on Paragraph Writing. The Outline of JACET Convention, 39, 15-16.

Shizuka, T. (1996). A Warning on underestimation of the effect of teacher correction in writing activity: Reflections based on a pilot study. Research Bulletin of Kantokoshinetsu Association of Teachers of English, 10, 25-33.

Tachibana, Y., Matsukawa, R., \& Zhong, Q. X. (1996). Attitudes and motivation for learning English: A cross-national comparison of Japanese and Chinese high school students. Psychological reports, 79(2), 691-700.

Taguchi, T., Magid, M., \& Papi, M. (2009). The L2 motivational self system among Japanese, Chinese and Iranian learners of English: A comparative study. In Z. Dörnyei \& E. Ushioda (Eds.), Motivation, Language Identity and the L2 Self (pp. 66-97). Bristol: Multilingual Matters. 
Taylor, G. (1989). The student's writing guide for the arts and social sciences. Cambridge: Cambridge University Press. Watanabe, H. (2013). A genre analysis of writing in Japanese university entrance examinations and teaching materials (Unpublished Masters dissertation). Sydney: University of Sydney.

Wang, C. (2013). A study of genre approach in EFL writing. Theory and Practice in Language Studies, 3(11), 2128-2135.

Woodward-Kron, R. (2002). Critical analysis versus description? Examining the relationship in successful student writing. Journal of English for Academic Purposes, 1(2), 121-143.

Woodward-Kron, R. (2005). The role of genre and embedded genres in tertiary students' writing. Prospect, 20(3), $24-41$. Yan, J., Zhang, W., Yu, Y., Chang, J., \& Ding, G. (2015). Research and practice on college English oral test-a case study of Beijing institute of petrochemical technology. English Language Teaching, 8(3), 121.

Yasuda, S. (2011). Genre-based tasks in foreign language writing: Developing writers' genre awareness, linguistic

knowledge, and writing competence. Journal of Second Language Writing, 20(2), 111-133.

Yoneyama, S. (1999). The Japanese high school: Silence and resistance. London: Routledge

Submit your manuscript to a SpringerOpen ${ }^{\circ}$ journal and benefit from:

- Convenient online submission

- Rigorous peer review

- Immediate publication on acceptance

- Open access: articles freely available online

- High visibility within the field

- Retaining the copyright to your article

Submit your next manuscript at $>$ springeropen.com 